\title{
Application of the plant-mix cold recycling technology of foamed asphalt to pavement reconstruction project: A case study
}

\author{
Yuliang Fan ${ }^{1, a}$, Yongqiang Deng ${ }^{2, b}$, Fenghui Chen ${ }^{1, c^{*}}$, Feng Wang ${ }^{1, d}$ \\ ${ }^{1}$ Sichuan Agricultural University, College of civil engineering, Dujiangyan, China \\ ${ }^{2}$ Hainan Zhenhai Engineering Co., Ltd., Haikou, China

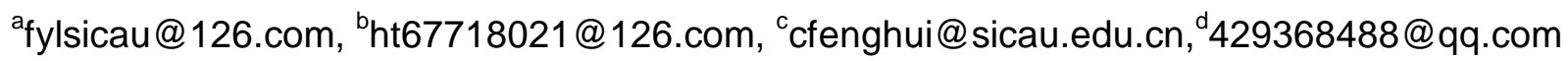

Key words: foamed asphalt; plant-mix cold recycling technology; pavement; reconstruction

Abstract. In the study, the plant-mix cold recycling technology of foamed asphalt (PCRTFA) was applied to a reconstruction project of a highway in Hainan province, China. The mix proportions of the raw materials and related parameters of PCRTFA were analyzed firstly. Then, the pavement construction test was carried out. After that, the reconstruction project of the highway was performed. At last, the construction technology and quality control were expounded. The case study shows that the PCRTFB can achieve the purpose of reusing resources and save construction costs. This study can provide technical reference for other similar pavement reconstruction projects in Hainan province.

\section{Introduction}

With the rapid economy growth in China, the road mileage is increasing year after year [1]. Until the end of year 2013, the Chinese road mileage has gotten to 4, 356, $200 \mathrm{~km}$. The road density is 0.4538 $\mathrm{km} / \mathrm{km}^{2}$. The road maintenance mileage is $4,251,400 \mathrm{~km}$, covered $97.6 \%$ of the total road mileage [2]. The maintenance of the road, especially for large and medium ones, could produce a large number of reclaimed asphalt pavement (RAP). Reuse of the RAP can avoid the pollution of the environment, and can realize the recycling of resources and save construction costs [3].

In recent years, a large number of scholars developed a series of technologies for reuse of RAP [4-10]. In these technologies, the plant-mix cold recycling technology of foamed asphalt (PCRTFA) has been widely concerned [9-14]. Compared with other technologies, PCRTFA can achieve the purpose of resource recycling, and can save the construction investment. Moreover, it also has the property of energy conservation and short construction period. Therefore, it has a high value of practical application for the maintenance of road. However, there exist some differences in the application of PCRTFA due to the different properties of RAP in different area. For the different properties of RAP, there need to design the different mix proportions of the raw materials and determine the related parameters of PCRTFA in the different practical projects. In addition, the corresponding construction technology and overall construction quality control is also need to be established for a specific project.

In this study, PCRTFA was applied to a reconstruction project of a highway in Hainan province, China. This study aims to provide technical reference and guidance for other similar pavement reconstruction projects in Hainan province.

\section{Project summary}

In this study, the highway of western Hainan province from Baimajing flyover to Bailian flyover needs to be reconstructed. The length of the highway is $99.715 \mathrm{~km}$. The total investment of the project is 12.9 $\times 10^{9}$ Yuan. The pavement reconstruction area is about $2.5 \mathrm{~km}^{2}$.

\section{The preparation and design of the mix proportions of the raw materials for PCRTFA}

Requirement of materials. The raw materials include five compositions, namely RAP, base asphalt, cement, gravel and water. RAP is required to be pretreated. The pretreatment method is based on the 
technical specifications [15]. The pretreated RAP needs to meet the requirement of Table 1, Table 2 and Table 3. Base asphalt is AH-70 road petroleum asphalt. The performance parameters of base asphalt need to be conformed to the technical specifications [15]. The strength grade of cement is more than 32.5, and other performance parameters of cement need to meet with the requirements of specifications [15]. For gravel, it also needs to conform to the requirements of specifications [16]. The used water is drinking water.

Table 1 The testing items and quality requirement of RAP

\begin{tabular}{|c|c|c|c|}
\hline Material & Test item & Technical requirement & Test method \\
\hline \multirow{4}{*}{ RAP } & Moisture content & Actual test & \multirow{4}{*}{ Ref. [15] } \\
\hline & Gradation of RAP & Actual test & \\
\hline & Contents of asphalt & Actual test & \\
\hline & Sand equivalent $(\%)$ & $>50$ & \\
\hline \multirow{4}{*}{ Asphalt of RAP } & Needle penetration & Actual test & \multirow{4}{*}{ Ref. [17] } \\
\hline & Viscosity at $60{ }^{\circ} \mathrm{C}$ & Actual test & \\
\hline & Softening point & Actual test & \\
\hline & Ductility at $15^{\circ} \mathrm{C}$ & Actual test & \\
\hline Coarse aggregate of RAP & $\begin{array}{l}\text { Acicular and flake-shaped } \\
\text { particle and crushing strength }\end{array}$ & Actual test & \multirow[t]{2}{*}{ Ref. [18] } \\
\hline Fine aggregate of RAP & Aggregate angularity & Actual test & \\
\hline
\end{tabular}

Table 2 The passing rate of aggregate gradation of RAP (\%)

\begin{tabular}{|c|c|c|c|}
\hline \multirow{2}{*}{ Sieve pore $(\mathrm{mm})$} & \multicolumn{3}{|c|}{ Passing rate of each sieve pore $(\%)$} \\
\cline { 2 - 4 } & Coarse particle & Medium grained particle & Fine particle \\
\hline 37.5 & 100 & $/$ & $/$ \\
\hline 26.5 & $85-100$ & 100 & $/$ \\
\hline 19 & $/$ & $90-100$ & 100 \\
\hline 13.2 & $60-85$ & $/$ & $90-100$ \\
\hline 9.5 & $/$ & $60-85$ & $/$ \\
\hline 4.75 & $25-65$ & $35-65$ & $45-75$ \\
\hline 2.36 & $30-55$ & $30-55$ & $30-55$ \\
\hline 0.3 & $10-30$ & $10-30$ & $10-30$ \\
\hline 0.075 & $6-20$ & $6-20$ & $6-20$ \\
\hline
\end{tabular}

Table 3 The technical requirements of RAP

\begin{tabular}{|c|c|}
\hline Test item & Technical requirement \\
\hline Spitting strength (Mpa) at $15{ }^{\circ} \mathrm{C}$ & $>0.4$ \\
\hline Wet-dry splitting strength ratio $(\%)$ at $15{ }^{\circ} \mathrm{C}$ & $>75$ \\
\hline Marshall stability $(\mathrm{KN})$ & $>5.0$ \\
\hline Marshall remnant stability test $(\%)$ at $40{ }^{\circ} \mathrm{C}$ & $>75$ \\
\hline Water susceptibility tensile strength ratio TSR $(\%)$ & $>70$ \\
\hline
\end{tabular}

Determination of foaming temperature and water consumption of base asphalt. According to the technical specifications [15], the suitable foaming temperature and water consumption of foaming of base asphalt were determined by the foaming experiment [19]. In the project, the suitable foaming temperature was $165^{\circ} \mathrm{C}$ and the water consumption was $3 \%$.

Determination of mix proportions of RAP, cement and gravel. In this project, the content of asphalt and water in the RAP of this project was $4.2 \%$ and $4.6 \%$, respectively. While the gradations of RAP, gravel and cement were shown in Table 4. According to the results of Table 4, the combined gradation curve was drawn by selecting of medium-size gradation (Fig.1). At last, in terms of gradation analysis of combined curve, the mix proportions were available. The mix proportion of RAP, gravel and cement was $80 \%, 18.5 \%$ and $1.5 \%$, respectively. 
Table 4 The gradation of RAP, gravel and cement

\begin{tabular}{|c|c|c|c|c|c|c|c|c|}
\hline \multirow{2}{*}{ Name of material } & $\begin{array}{c}\text { Material specification } \\
(\mathrm{mm})\end{array}$ & \multicolumn{5}{|c|}{ Mass percent of passing the following sieve pore (\%) } \\
\cline { 3 - 9 } & 26.5 & 19 & 9.5 & 4.75 & 2.36 & 0.3 & 0.075 \\
\hline RAP & $0-26.5$ & 100 & 91.7 & 68.1 & 44.3 & 30.4 & 7.3 & 2.9 \\
\hline gravel & $0-3$ & 100 & 100 & 100 & 100 & 91.8 & 21.8 & 12.5 \\
\hline cement & & 100 & 100 & 100 & 100 & 100 & 100 & 98.6 \\
\hline
\end{tabular}

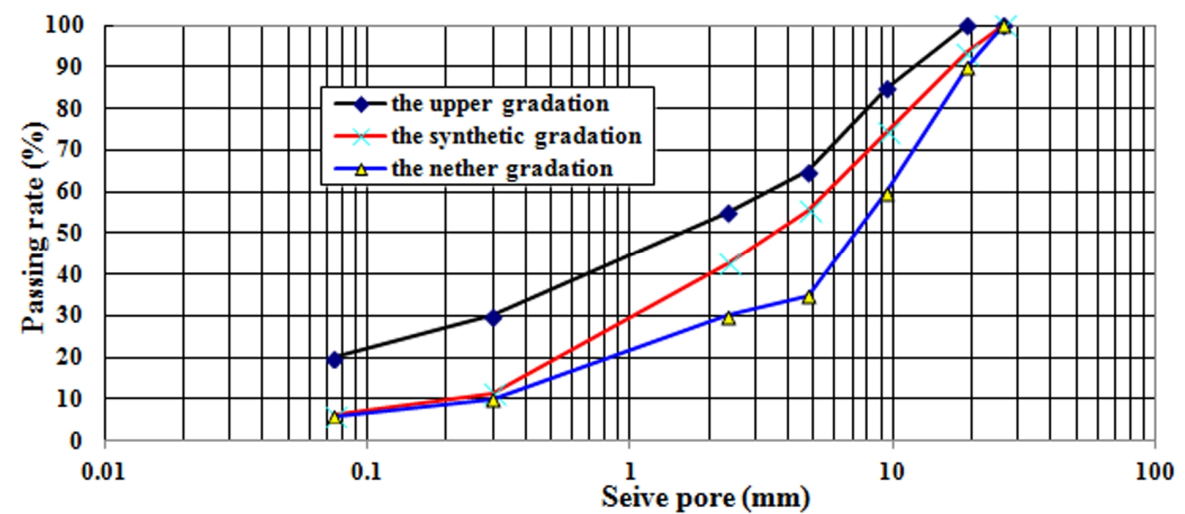

Fig. 1 The combined gradation curve of RAP, cement and gravel

Determination of maximum dry density and optimum moisture content of the mixed materials. According to the technical specifications [15] and the guidance [20], the dry density of the mixed material samples were determined by carrying on compaction test of five kinds of RAP, which the moisture content is $4.5 \%, 5.0 \%, 5.5 \%, 6.0 \%$ and $6.5 \%$, respectively, under the fixed condition of the foamed asphalt content (3\%). Based on the results of compaction test, the maximum dry density and optimum moisture content were obtained with regression analysis between the dry density and corresponding water contents of the samples. The maximum dry density was $2.007 \mathrm{~g} / \mathrm{cm}^{3}$ and the optimum moisture content was $5.3 \%$.

Determination of the optimal consumption of foamed asphalt. Maintaining the optimal moisture content $(5.3 \%)$, the optimal consumption of foamed asphalt was determined by Marshall experiment [20]. In Marshall experiment, the Marshall test-samples were made with different consumptions of foamed asphalt (i.e., $1.5 \%, 2.0 \%, 2.5 \%, 3.0 \%$ and $3.5 \%$ ). After maintenance of the Marshall test-samples in terms of the specifications [15], the properties of the test-samples, such as splitting strength, splitting strength ratio and resistance to deformation of high temperature etc., were tested. According to the results of Marshall experiment, the optimal consumption of foamed asphalt is $2.5 \%$ in the project.

Verificaiton of mix proportions of the raw materials. Through test of rutting testing, immersion Marshall test, crack resistance test of low temperature, fatigue capability test, etc. [20], the properties of test-samples, which were made under the conditions of the optimal mix proportions of the raw materials, were evaluated. The evaluation results showed that the test-samples conform to the requirement of pavement application. Then, the mixed materials were directly used in the practical project to verify the mix proportions of the raw materials [12]. The results of the practical verification confirmed the optimal mix proportions of the raw materials.

\section{Construction technology process}

In the project, the construction technology contains six processes, namely obtainment of RAP, pretreatment of RAP, mix of the raw materials, transportation of mixed materials, paving and rolling, and maintenance of the paving layer. The detail construction process is described in the following:

Obtainment of RAP. The design milling thickness of old highway is $10 \mathrm{~cm}$. The milling was carried out by the milling machine (Wittgen W2000, Germany). The milled RAP was transported to mix station. In the milling, it is necessary to take measures to prevent the waste of cement stabilization 
broken stone base to mix into RAP. In the practical project, the speed of milling is $6-8 \mathrm{~m} / \mathrm{min}$. Under the speed, the gradation of RAP is approaching to target gradation.

Pretreatment and stacking of RAP. After the RAP was transported to pretreatment field, the RAP was broken and sieved. The pretreated RAP was stacked to use. The piles of the pretreated RAP were covered with water-proof material to assure the stable moisture content. The use principle of the pretreated RAP is which comes first which is prior to use.

Mix of the raw materials. In order to obtain homogeneous mixture, in the practice, the mixture process was produced with the cold recycling mix station (Wittgen KMA220, Germany). In the project, the theoretical production was $220 \mathrm{t} / \mathrm{h}$.

Transportation of mixed materials. In the project, the mixed materials were transported by large tonnage autodumper. In the transport process, it was needed to prevent the rapid evaporation of water in the mixed materials and keep the rain off.

Paving and Rolling. In the project, the paving process was performed in steps with the pavers with a digital controller of travel system. The paving altitude was controlled by auto-elevator device [21]. The velocity of paving is uniformal and continuous within 1-3 m/min. Rolling of the paving layer was carried on with combined rolling process using double vibratory steel roller, single vibratory steel roller, and pneumatic tyre roller. The speed of vibratory steel roller was controlled in $3 \mathrm{~km} / \mathrm{h}$, while the speed of pneumatic tyre roller was controlled in $4 \mathrm{~km} / \mathrm{h}$. The rolling sequence and the other control requirement can be found in references $[15,20]$.

Maintenance of the paving layer. According to technical specifications [15], the maintenance period of the paving layer was 8 days, while the moisture content of the paving layer was less than $2 \%$ at the end of the maintenance period. After finishing the maintenance, the structure layers were continuously constructed on the paving layer.

\section{Control Measures of construction quality and management}

In the construction, the specifications and standards [16, 18, 19-24] should to be strictly executed. Meanwhile, there is need to strictly control the following aspects: the mix proportions of the raw materials, the gradation of RAP, foaming condition of asphalt, and moisture content.

\section{Conclusions}

The pavement reconstruction project was finished on October 23th, 2012. The project quality is stable in three years. The project demonstrated that PCRTFA is a reliable technology. PCRTFA can achieve the purpose of reusing resources and save engineering costs. The research provided the technical reference and guidance for other similar pavement reconstruction projects in Hainan province.

\section{References}

[1] Q. Liu: Tire Ind. Vol. 34(2014), p. 200. (In Chinese)

[2] National Bureau of Statistics of the People's Republic of China: China Statistics Yearbook (China Statistics Press, China 2014).

[3] T. Wang and P. Hao: Chin. For. Hway. Vol. 33(2013), p. 325. (In Chinese)

[4] J. Yang: Jiangxi Bldg. Mat. Vol. 156(2015), p. 168. (In Chinese)

[5] Z. Huang and L. Du: Chin. Water Trans. Vol. 13(2013), p. 282. (In Chinese)

[6] W. Wang and C. Liu: Sci. Tech. Info. Heilongjiang Vol. 17(2011), p. 223. (In Chinese)

[7] Y. Gao: Hways. Automotive Appl. Vol. 168(2015), p. 157-160. (In Chinese)

[8] Q. Zhang: Econ. Res. Guide Vol. 242(2014), p. 25. (In Chinese) 
[9] Y. Shu: Hways. Automotive Appl. Vol. 143(2011), p. 117. (In Chinese)

[10] J. Cao: Jour. Hebei Eng. Tech. College Vol. 23(2014), p.54. (In Chinese)

[11] Y. Kui and Z. Lu: Tech. Hway. Trans. Vol. 17(2015), p. 53. (In Chinese)

[12] T. Luo, J. Jing and C. Chen: Western Chin. Comm. Sci. Tech. Vol. 10(2015). p. 1. (In Chinese)

[13] G. He, C. Cao and H. Han: Jour. Hway. Trans. Res. Dev. Vol. 21(2004), p. 9. (In Chinese)

[14] K. Gui and G. Gui: Tech. Hway. Trans. Vol. 15(2014), p. 49. (In Chinese)

[15] Ministry of Transport of the People's Republic of China: Technical specifications for highway asphalt pavement recycling (JTG F41-2008) (People's Communication Press, China 2008).

[16] Ministry of Transport of the People's Republic of China: Technical specifications for construction of highway asphalt pavements (JTG F40-2004) (People's Communication Press, China 2004).

[17] Ministry of Transport of the People's Republic of China: Standard test methods of bitumen and bituminous mixtures for highway engineering (JTG E20-2011) (People's Communication Press, China 2011).

[18] Ministry of Transport of the People's Republic of China: Test methods of aggregate for highway engineering (JTG E42-2005) (People's Communication Press, China 2005).

[19] F. Li, W. Zeng, and J. Xu: Jour. Bldg. Mat. Vol. 18(2015), p. 162. (In Chinese)

[20] Jiangsu Traffic Science Research Institute: The guidance compilation for reconstruction project of highway pavement of north Hainan (Jiangsu Traffic Science Research Institute, China 2011).

[21] C. Li: Guangdong Bldg. Mat. Vol. 15(2008), p. 139. (In Chinese)

[22] Ministry of Transport of the People's Republic of China: Test methods of soils for highway engineering (JTG E40-2007) (People's Communication Press, China 2007).

[23] Ministry of Transport of the People's Republic of China: Technical specification for construction of highway safety facilities (JTG F71-2006) (People's Communication Press, China 2007).

[24] Ministry of Transport of the People's Republic of China: Safety technology specifications for highway engineering construction (JTG F90-2005) (People's Communication Press, China 2005). 